\title{
Arquidiocese de Mariana, Teologia da Libertação e Emergência do Movimento dos Atingidos por Barragens do Alto Rio Doce (MG)
}

\author{
Fabrício Roberto Costa Oliveira* \\ Franklin Daniel Rothman**
}

\section{Introdução}

$\mathrm{O}$ objetivo deste estudo foi demonstrar como, em um momento em que a cúpula da Igreja Católica procurava diminuir o ativismo político do catolicismo, a Arquidiocese de Mariana (MG) mostrou-se mais receptiva às idéias da Teologia da Libertação e abriu espaço para que setores progressistas pudessem apoiar o Movimento dos Atingidos por Barragens do Alto Rio Doce (MAB-ARD), de Minas Gerais.

Intrigante é o fato de que, enquanto muitas dioceses brasileiras atuavam apoiando movimentos populares nas décadas de 1970 e 1980, a Arquidiocese de Mariana legitimava a ditadura militar e não apoiava manifestações populares contestatórias das ordens econômicas, sociais e políticas vigentes. Na década de 1990, quando houve uma investida do Vaticano no sentido de frear a atuação dos progressistas e um claro apoio a setores ligados à Renovação

* Doutor em Sociologia pela University of Wisconsin-Madison e Professor Associado do Departamento de Economia Rural da Universidade Federal de Viçosa. Endereço eletrônico: frothman@ufv.br.

*** Licenciado e Bacharel em História pela Universidade Federal de Ouro Preto (UFOP), Mestre pelo Programa de Mestrado em Extensão Rural da Universidade Federal de Viçosa (UFV), doutorando do Programa de Pós-Graduação em Ciências Sociais em Desenvolvimento, Agricultura e Sociedade pela Universidade Federal Rural do Rio de Janeiro (UFRRJ) e Professor Substituto do Setor de Sociologia e Antropologia da UFOP. Endereço eletrônico: frcoliveira@yahoo.com.br.

1 Este artigo foi originalmente apresentado no XIII Congresso da Sociedade Brasileira de Sociologia, realizado de 29 de maio a $1^{\text {o }}$ de junho de 2007 , em Recife (Pernambuco). 
Carismática Católica, a Arquidiocese de Mariana destacou-se por sua atuação progressista, apoiando o MAB e mostrando-se engajada com os problemas sociais da população de sua jurisdição eclesiástica.

Entre os grupos da sociedade civil apoiados pela Arquidiocese, o MAB-ARD merece especial atenção devido à sua grande atuação na região, bem como por sua relação com a Arquidiocese ${ }^{2}$. Diante disso, este trabalho analisa as transformações institucionais e ideológicas ocorridas na Arquidiocese - como, por exemplo, a convergência de fatores internos e externos à Igreja Católica que criaram uma oportunidade política que facilitou a emergência do movimento progressista de religiosos dentro da Arquidiocese, a qual, por sua vez, contribuiu para a organização do MAB-ARD - e analisa como se dá o apoio da Arquidiocese a esse Movimento.

Além da introdução, em que são apresentados os objetivos deste estudo, este texto foi dividido em quatro partes: na primeira, é feita uma explanação da teoria utilizada; na segunda, são explicitados os processos de transformação na Arquidiocese de Mariana; na terceira, mostra-se como as instituições progressistas da Igreja contribuíram para a mobilização e construção de uma "consciência insurgente" com os atingidos pelas barragens e a organização do MAB-ARD; por fim, encontram-se na última parte o resumo e as conclusões.

\section{Oportunidades políticas, frames e estruturas de mobilização}

Os pesquisadores de movimentos sociais de diversos países que representam diferentes tradições teóricas têm analisado os mesmos três conjuntos de fatores nas pesquisas sobre esses movimentos e/ou revoluções. Esses conjuntos podem ser descritos como: 1) estruturas de oportunidades políticas e constrangimentos que confrontam o Movimento; 2) formas de organização disponíveis aos insurgentes e 3) processo coletivo de interpretação, atribuição e

2 Esse fato pode ser explicitado pelo posicionamento da Arquidiocese em seu jornal oficial, assim como por declarações feitas pelo arcebispo e pelos padres, e também porque o Movimento utiliza-se de recursos da Arquidiocese, como escritório, telefone e secretária. 
construção social que faz mediação entre a oportunidade e a ação (MCADAM, MCCARTHY \& ZALD, 1996a, p. 2) ${ }^{3}$.

Segundo Smith (1991), a Teologia da Libertação constituise em um movimento social na medida em que não é apenas um campo de idéias ou crenças, mas uma tentativa de mobilizar atores sociais coletivos contra antagonistas para a promoção da mudança social. Nesse sentido, 1) oportunidades políticas, 2) estruturas de mobilização e 3) processos de framing constituem importantes pontos de análise para o entendimento do Movimento da Teologia da Libertação na América Latina.

Neste trabalho, esses conceitos foram utilizados na perspectiva de analisar a consolidação do MAB-ARD e o movimento de difusão de idéias religiosas progressistas, associadas à Teologia da Libertação, na Arquidiocese de Mariana. Esses movimentos contaram com padres e leigos na tentativa de promover idéias e práticas religiosas associadas à Teologia da Libertação. $\mathrm{O}$ contexto em que esses grupos estavam inseridos pode ser analisado de acordo com o conceito de estrutura de oportunidades políticas, as quais são definidas por Tarrow como:

[...] sinais para que atores sociais ou políticos encorajem-se ou desencorajem-se no uso de seus recursos internos para formarem movimentos sociais. Meu conceito de oportunidades políticas enfatiza não somente estruturas formais como instituições estatais, mas estruturas de conflito e de aliança que provém recursos e opõem constrangimentos externos aos grupos (TARROW, 1996, p. 54).

Smith (1991, p. 59) considera a abertura ideológica como fonte de oportunidade política: "abertura ideológica designa um ambiente social que tolera ou incentiva a consideração séria de idéias e visões de mundo novas, alternativas ou críticas, até subversivas" e "pode aumentar significativamente a oportunidade política para grupos para se tornar movimento social" (ROTHMAN, 1993, p. 18).

3 McAdam, Tarrow e Tilly (2001) identificaram os seguintes fatores que marcam a agenda dos movimentos sociais no processo de mudança social: 1) oportunidades e constrangimentos políticos; 2) formas de organização; 3) repertório simbólico (framing) e 4) repertório contencioso. Esse conjunto de fatores é conhecido na literatura norte-americana como o political process model, traduzido como a teoria de mobilização política (GOHN, 2002). 
Para emergência e desenvolvimento de um movimento social, estruturas de oportunidades políticas se fazem necessárias, mas são insuficientes, necessitando-se também de estruturas de mobilização. Estas, segundo McCarthy (1996), podem ser entendidas como as diversas maneiras de engajamento numa ação coletiva que engloba "repertório tático" particular e formas de "organização particulares do movimento social", incluindo os locais de estruturas de micromobilização, que, a priori, não visavam à mobilização, mas são lugares onde ela pode ser gerada. Isso inclui as unidades familiares, redes de amizade ${ }^{4}$, associações voluntárias, unidade de trabalho etc. (MCCARTHY, 1996, p. 141).

Melucci $(2001$, p. 97) destaca essa questão ao afirmar que "a solidariedade do grupo não está separada da busca pessoal e das necessidades afetivas e comunicacionais dos membros, na sua existência cotidiana”. Assim, esse autor defende a idéia de que os impulsos de conflitos sobrevivem e se reproduzem para além de mediações institucionais, sendo este um importante fator que impede a dispersão das diversas "células”; assim, as relações de solidariedade dos atores sociais na vida cotidiana constituem importantes fatores de coesão social para a mobilização coletiva.

Nessa mesma perspectiva, Tarrow $(1998$, p. 22) afirma que, apesar de a decisão de participar de uma ação coletiva ser individual, é no grupo de relações sociais e nas redes de ligação em que essa pessoa se insere que a decisão é ativada e sustentada. Esse caráter dos movimentos sociais tem sido mostrado por diversas pesquisas sobre os movimentos sociais (cf. MCADAM, MCCARTHY \& ZALD, 1996a).

Entretanto, a combinação entre estruturas de oportunidades políticas e estruturas de mobilização oferece aos grupos sociais importantes condições para a emergência de movimentos sociais, mas elas são insuficientes para a ação coletiva, uma vez que, juntos, esses fatores apenas oferecem uma certa estrutura potencial para a ação (MCADAM, 1982, p. 48). A geração de insurgência envolve, também, a transformação de consciência: as pessoas começam a crer

4 O papel das estruturas informais - ou seja, os contatos diários - tem sido tratado como um fator importante para os movimentos sociais; muitas vezes, é considerado como micromobilização (MCCARTHY, 1996, p. 143). 
que as autoridades são injustas; a deixar de ser fatalistas, afirmando seus "direitos", que implicam demandas para mudança; e a sentir que têm o poder para mudar sua condição (PIVEN \& CLOWARD, 1979). McAdam (1982) usou o conceito de cognitive liberation para esse processo de transformação de consciência.

Smith denominou esse processo de insurgent consciousness, aqui traduzido como consciência insurgente e entendido como o estado coletivo de entendimento de que a mudança social é viável (SMITH, 1991, p. 62). Para Smith, a consciência insurgente só emerge no momento em que um grupo de pessoas adota um frame de injustiça (idem, p. 63). Esse conceito de frame é útil para entender o processo de geração de insurgência.

Mediando entre oportunidade, organização e ação estão os significados e definições que as pessoas compartilham de suas situações. Nesse sentido, para a participação em um movimento social, o mínimo de que as pessoas precisam é o sentimento de que, agindo coletivamente, elas podem obter resultados positivos (MCADAM, MCCARTHY \& ZALD, 1996a, p. 5).

Esse sentimento requer características particulares nos atores sociais para que estes se sintam convencidos de que são capazes de mudar suas condições (idem). Condicionando a presença ou ausência dessas percepções sociais, há uma complexa dinâmica de psicologia social a que diversos autores têm se referido como framing processes.

McAdam, McCarthy e Zald (1996a, p. 7) definem framing processes como "esforços estratégicos conscientes de grupos de pessoas que compartilham compreensões de mundo que legitimam, definem e motivam a ação coletiva"5. Para Smith (1991, p. 93), frame é "um sistema de interpretação que os indivíduos utilizam para ordenar a realidade, fazer eventos significativos, organizam experiências, e guiam a ação".

Rothman (1993, p. 22-32), por sua vez, argumenta que, nos estudos dos movimentos de resistência a deslocamentos involuntá-

5 No original: "conscious strategic efforts by groups of people to fashion shared understandings of the world and of themselves that legitimate and motivate collective action" (MCADAM, MCCARTHY \& ZALD, 1996a, p. 6). 
rios, há a necessidade de uma explicação mais relacional, interativa, e aponta o trabalho de Melucci para complementar a abordagem de pesquisadores como McAdam (1982), McAdam, McCarthy e Zald (1996a) e Tarrow (1998), para explicar a geração de insurgência. Melucci enfatiza a ação coletiva como um processo interativo que, frequientemente, envolve grupos de amizade e organizações comunitárias (ROTHMAN, 1993, p. 25). Ele destaca a importância de "sistemas relacionais intermediários" que produzem definições compartilhadas do campo de oportunidades e constrangimentos disponíveis à ação coletiva. Nesse sentido, Melucci conceitua identidade coletiva como "definição interativa e compartilhada produzida por um número de indivíduos (ou grupos, em um nível mais complexo), relacionada à orientação de suas ações e do campo de oportunidades e constrangimentos nos lugares em que estas ações se fazem" (MELUCCI, 1996, p. 70).

\section{1964 a 1989: a Teologia da Libertação, o Mobon e os processos de transformação social na Arquidiocese de Mariana}

No Brasil Colônia, a Arquidiocese de Mariana exerceu enorme influência na sociedade mineira e se consolidou como grande formadora de clérigos, sendo uma instituição de grande importância na consolidação dos interesses portugueses, tendo sido, por isso, de grande relevância na manutenção do status quo. No século XIX, o processo de romanização tinha a Arquidiocese de Mariana como importante ator, já que Dom Viçoso, bispo de Mariana, era um dos principais expoentes do catolicismo brasileiro que buscava por um catolicismo "oficial", o qual procurava romper com as práticas religiosas populares (OLIVEIRA, 1985). Durante a primeira metade do século XX, a atuação conservadora, tanto da Igreja Católica brasileira quanto da Arquidiocese de Mariana, continuou a se fazer consistente, inclusive às vésperas do golpe de 1964.

Não obstante a postura conservadora da Igreja Católica, no início da década de 1960, acontecia o Concílio Vaticano II (1962-1965), que se consolidou como um evento de grande impor- 
tância para a emergência de idéias associadas à Igreja progressista ${ }^{6}$ e à Teologia da Libertação, que podem ser entendidas como uma escola romana de pensamento que emergiu na América Latina no final da década de 1960 (SMITH, 1991). Seus postulados defendem que o papel da Igreja é o de participar da promoção social e de lutar pela justiça econômica (idem).

Segundo Boff e Boff (2001, p. 74), "podemos entender a Teologia da Libertação como aquela reflexão de fé da Igreja que tomou a sério a opção preferencial e solidária com os pobres". Para Scherer-Warren (1996, p. 32-33), a Teologia da Libertação:

[...] nasce e se desenvolve enquanto expressão de problemas da realidade social latino-americana, no desejo de transcendê-la através da criação de uma sociedade mais justa e igualitária. Trata-se do encaminhamento de uma nova visão para o papel da Igreja, da prática cristã e do pensar teológico, até então apoiado numa teologia feita a partir da realidade exógena européia.

Diferenças de definições e enfoque à parte, pode-se afirmar que grupos religiosos progressistas ${ }^{7}$ engajados em transformações sociais utilizaram idéias da Teologia da Libertação na legitimação de diversas mobilizações sociais em oposição a diversas ditaduras por toda a América Latina. As Comunidades Eclesiais de Base (CEBs) definidas como grupos católicos que se reúnem regularmente para discutir a bíblia, relacionando os escritos desta com os problemas sociais que vivem - foram muito importantes na difusão das idéias da Teologia da Libertação.

A presença das CEBs se fez então como importante parte da estrutura de mobilização. Esses pequenos grupos, por meio da

6 "O termo católico progressista enfrenta certa controvérsia ao se referir aos católicos da Teologia da Libertação e é criticado por vários autores. Contudo, apesar de seus limites, constitui um termo consagrado na literatura e permite englobar todos os católicos que optam por uma prática religiosa e um discurso que pode ser associado à Teologia da Libertação" (MARIZ, 2001, p. 20).

7 "Os progressistas promovem atividades para reformas sociais, políticas e econômicas no caminho da democracia e modernização econômica para melhorar o bem-estar da população latino-americana e se engajam em críticas sociais" (SMITH, 1991, p. 51). 
organização dos leigos, das reflexões acerca do cotidiano e dos problemas diários tendo como referência a bíblia, além do apoio de padres e bispos para a mobilização popular, acabaram gerando e/ou apoiando vários movimentos sociais por todo o país, tanto no meio urbano quanto no rural. A Teologia da Libertação e as CEBs tiveram grande influência na emergência de movimentos sociais nas décadas de 1970 e 1980 (cf. PETRINI, 1984; GAIGER, 1987; ROTHMAN, 1993; IOKOI, 1996; LESBAUPIN, 2000; LESBAUPIN et alii, 2004).

$\mathrm{Na}$ Arquidiocese de Mariana não havia CEBs em toda a sua extensão territorial, "mesmo porque a Arquidiocese como um todo não havia feito sua opção pelas CEBs"8. Apesar disso, em fins da década de 1960, um grupo de católicos de dentro da Arquidiocese e de fora dela mobilizou pessoas para a promoção de idéias religiosas progressistas.

O padre Daniel, importante incentivador de CEBs na Arquidiocese, narra ${ }^{9}$ seu trabalho de mobilização e a importância de seu contato com a diocese vizinha da seguinte forma:

Aí a Diocese de Mariana divide com a Diocese de Caratinga e a gente vendo a beleza da diocese de Caratinga, por que eu visitava Divino, e faz divisa com Pedra Bonita, Santa Margarida, dividindo com Pedra Bonita, a gente olhando vendo as coisas, sobretudo Divino, que Santa Margarida na ocasião era um Padre Holandês, ele não olhava muito para esse lado de CEBs não. Mas Divino era maravilha lá. E visitando lá a convite do padre e também celebrando cá, a gente vendo a atitude dos leigos, aí resolvi, conforme se diz né, "deixa a abóbora passar debaixo da cerca”, não é. Assim nós

8 A análise documental foi importante, pois forneceu mais subsídios para a compreensão das transformações na postura institucional da Arquidiocese de Mariana, seu posicionamento diante das questões políticas, bem como sua relação com o MAB-ARD. Os documentos analisados encontram-se no Arquivo Eclesiástico da Arquidiocese de Mariana (cf. O Pastoral, ano V, n. 50, ago.1995).

9 Por meio de entrevistas orais, obteve-se uma série de narrativas de suma importância para este trabalho. Foram entrevistados o arcebispo Dom Luciano e padres e leigos da Arquidiocese de Mariana que têm acompanhado transformações que vêm ocorrendo nessa instituição, no que diz respeito à sua postura frente aos setores progressistas e ao MAB. As entrevistas foram gravadas e, posteriormente, transcritas e analisadas. 
começamos também, Pedra Bonita, Sericita, São Domingos, Ribeirão São Domingos e as coisas foram crescendo sabe ${ }^{10}$

Por meio da narrativa do padre Daniel, pode-se perceber que, apesar do caráter institucional da Igreja Católica, foram as redes de ligações informais e as relações estabelecidas pelo padre e leigos com outros grupos da vizinha Diocese de Caratinga que foram fundamentais para um contato mais efetivo para emergência das CEBs na Arquidiocese de Mariana.

As relações solidárias entre os padres e o engajamento dos leigos formaram uma importante estrutura de mobilização capaz de proporcionar condições de emergência de práticas mais progressistas na Arquidiocese de Mariana. Boa parte dessa estrutura de mobilização tem a ver com o trabalho dos leigos, que, muitas vezes, insatisfeitos com as mensagens religiosas da Arquidiocese de Mariana, procuraram em livros, panfletos e, principalmente, na vizinha Diocese de Caratinga mensagens que satisfaziam melhor aos seus anseios políticos e religiosos.

Nesse sentido, o contato com uma diocese que tinha um bispo engajado na criação de CEBs, produzia materiais para esses grupos e contava com padres e uma população engajada mostrava-se fundamental para leigos e padres da Arquidiocese de Mariana que se interessavam por essas idéias e, internamente, não contavam com o aval da instituição.

$\mathrm{O}$ contato com a Diocese de Caratinga foi importante. $\mathrm{Na} \mathrm{Ar}-$ quidiocese, à medida que iam se criando CEBs, os grupos católicos progressistas iam discutindo os problemas da sociedade e a idéia da necessidade de maior envolvimento da religião nas questões sociais aumentava, o que era um facilitador para a construção de uma identidade coletiva progressista, que se tornava mais consistente à medida que se fortalecia a estrutura de mobilização pela solidariedade, amizade e ligação entre os atores sociais.

O padre Daniel ficou na região onde trabalhava havia muito tempo, porque, segundo ele, "o bispo tinha mais ou menos essa

10 Entrevista com o padre Daniel, realizada em Mariana em outubro de 2004. 
idéia, 'se tá bem, fica', a não ser que queira sair". Fazendo esse trabalho, o padre afirma:

Eu consegui da Alemanha, através do bispo Dom Oscar, consegui ganhar uma Kombi zero quilômetro para a evangelização por causa das CEBs, levando curso, buscando cursos. Dom Cavati, muitas vezes, nós fomos lá e, no intercâmbio, no meio da paróquia também, rodando, levando líderes, participamos de muitos cursos na Diocese também utilizando desse veículo, então foi uma beleza, né? ${ }^{11}$

Fato interessante da pesquisa foi ter percebido que, apesar de o arcebispado não ter se empenhado na promoção de CEBs, ele não impedia os padres de a promoverem, desde que isso não trouxesse consequiências "negativas" 12 para a Arquidiocese, como, por exemplo, a "politização excessiva", que era vista como um grande mal ao catolicismo.

Entretanto, mesmo com essa postura de evitar o envolvimento político de grupos religiosos na Arquidiocese de Mariana, criava-se um cenário propício à mobilização progressista: a oposição de católicos progressistas à ditadura militar no Brasil, as idéias do Concílio Vaticano II, o contato com a Diocese de Caratinga e a existência de um grupo de padres e leigos que objetivavam a veiculação de idéias religiosas progressistas na região. Nessa perspectiva, pode-se dizer que acabou se formando uma estrutura de oportunidade política favorável aos grupos progressistas da Arquidiocese de Mariana.

A mobilização progressista ainda era incipiente; as CEBs que se criavam tinham ação limitada. O padre Douglas refere-se a elas como sendo "não tão politizadas", mas era a emergência de novas idéias e novas formas de práticas religiosas, as quais, muitas vezes, não eram bem-vistas pela elite eclesiástica local. Segundo o padre Claret $^{13}$ :

11 Dom Cavati é uma cidade do Leste de Minas Gerais (faz parte da Arquidiocese de Caratinga), onde se localiza a sede e a casa de cursos do Mobon, que tem idéias religiosas progressistas e exerceu importante influência na Arquidiocese de Mariana.

12 Negativas segundo a visão da elite eclesiástica da Arquidiocese de Mariana, evidentemente.

13 O Padre Antônio Claret Fernandes é um dos principais assessores do MAB-ARD; a entrevista com ele foi realizada em outubro de 2004, em Ponte Nova (MG). 
havia até uma coisa interessante na época porque a Diocese de Caratinga e a de Itabira eram bem malvistas pela Arquidiocese e a gente acabava incorporando aquilo de que a nossa Diocese era melhor. Como se a nossa Diocese é que era a mãe certa, porque elas desmembraram de cá. Como se fosse assim a saída das filhas rebeldes, mas aí nós fomos entendendo que lá as pessoas participavam muito mais e elas vieram entrando por ali, na região de Sericita.

Esse é um depoimento ilustrativo de como alguns padres e grupos de religiosos da Arquidiocese pensavam a respeito das dioceses engajadas com a criação de CEBs e como, a partir do contato com as dioceses vizinhas e da reflexão, muitos religiosos começavam a perceber os benefícios que a criação de CEBs poderia trazer para a Arquidiocese, ou seja, havia um processo de transformação da visão que se tinha da religião e da vida social, dentro de um framing process.

No intuito de continuidade dessa transformação, integrantes do Movimento da Boa Nova (Mobon) eram convidados para ministrar cursos na Arquidiocese de Mariana. Segundo um dos fundadores e presidente do Mobon (em 2004), o objetivo do trabalho que realizavam era levar os leigos à reflexão e dar-lhes liberdade para falar de sua realidade, proposta que apresentava bastante afinidade com a Teologia da Libertação.

Conforme alguns depoimentos, o Mobon ${ }^{14}$ exerceu grande influência no território da Arquidiocese de Mariana na década de 1970, mas é difícil precisar as visitas e o trabalho dos integrantes do Movimento antes de 1979. Depois dessa data, o Mobon inaugurou uma casa de cursos na cidade de Dom Cavati (MG), para onde mais de 700 pessoas, de mais de 15 localidades da Arquidiocese de Mariana, viajavam e faziam diversos cursos. Dessa forma,

14 As idéias do Mobon têm pontos comuns com a Teologia da Libertação, por incentivar a reflexão e a prática cristã no sentido de promover a justiça social e política. Nesse sentido, o Mobon acredita que "não basta declarar fé em Deus e frequientar a Igreja. É indispensável envolver-nos na política. E esse envolvimento não pode afastar-nos da espiritualidade. Na medida que os cristãos lavam suas mãos diante da política, os políticos corruptos ficam livres para ir ajeitando as coisas de acordo com seus interesses. Interesses deles e daqueles que bancaram suas campanhas" (MOBON, 198?). 
consolidava-se ainda mais a estrutura de mobilização, que já se mostrava consistente com a presença de membros do Mobon na Arquidiocese, a qual, a partir de então, passava a contar com uma importante infra-estrutura: a casa de curso.

O movimento religioso promotor de idéias progressistas na Arquidiocese de Mariana continuava firme na década de 1980; contudo, mesmo nessa década, em que o medo do comunismo não era tão grande como na década de 1960, segundo o padre Douglas, o seminário da Arquidiocese ainda se mostrava contrário às idéias da Teologia da Libertação. Assim ele diz:

[...] Depois vim pra cá e entrei para o seminário em 1981, comecei estudar teologia, mas ainda nesse ambiente que era fechado, eu fiquei pouco tempo, eu fiquei um ano e meio. No meu período chegou-se mesmo a se cogitar da parte de Dom Oscar até a proibição, mas ele não fez isso não, mas foi cogitado até a proibição de livros de Leonardo Boff. Quer dizer, era outro tipo de perspectiva. Não foi feito, na própria formação, houve quem ponderasse com ele, não era o ideal, que as pessoas deveriam conhecer até para serem críticos, mas enfim, o lado social não se falava tanto, a não ser em alguma leitura e conversas mais nossas.

De acordo com o relato, a Teologia da Libertação só era permitida na Arquidiocese de Mariana com restrições. Nos jornais da Arquidiocese eram muitas as notícias que reafirmavam os cuidados que se deveria ter com essa Teologia para não confundi-la com questões políticas e sociais. Assim, mesmo depois de passados os momentos difíceis da ditadura militar, a Arquidiocese continuava tentando impedir que idéias progressistas nela se tornassem hegemônicas.

Como afirmou o padre Douglas, as críticas às condições sociais e políticas aconteciam sem empenho dos grupos dirigentes da Arquidiocese, que seguiam à risca a tentativa da hierarquia católica romana de tentar frear a atuação progressista da Igreja Católica. A carta apostólica endereçada aos bispos brasileiros dizia que a Igreja não deveria se envolver em questões sociais em detrimento de sua missão especificamente religiosa (HIGUET, 1984).

De acordo com Prandi e Souza (1996, p. 62-63), o Papa "se mostrava bastante alinhado às tendências carismáticas e bem distantes 
da opção pelos pobres da Teologia da Libertação". Essa política do Vaticano acabou, paradoxalmente, beneficiando os grupos progressistas da Arquidiocese de Mariana, pois uma das estratégias utilizadas para desmantelar a progressista Arquidiocese de São Paulo foi:

[...] a transferência de Dom Luciano Mendes de Almeida, presidente da Conferência Nacional dos Bispos do Brasil (CNBB) e ex-auxiliar da arquidiocese paulista para arquidiocese mineira de Mariana, uma das mais antigas na história religiosa do país, mas com pouca expressão sócio-política. Esta transferência foi feita à revelia do cardeal D. Paulo Evaristo Arns, pertencente à ala esquerda do clero brasileiro, que desejava que D. Luciano sucedesse no arcebispado de São Paulo. Além disso, como se sabe, com o objetivo de esvaziar o poder de D. Paulo Evaristo Arns, que dirige a maior arquidiocese, estudos estão sendo feitos em Roma para dividir a arquidiocese paulistana em quatro regiões episcopais - Osasco, Itapecirica da Serra, Santo Amaro e São Miguel Paulista, que são as principais áreas de ação pastoral do cardeal e de maior força popular (VALENTE, 1989, p. 88; sem grifos no original).

A tentativa de esvaziamento de poder de Dom Evaristo Arns acabou trazendo benefícios para os progressistas da Arquidiocese de Mariana, pois Dom Luciano ${ }^{15}$ era um dos grandes nomes do grupo progressista das décadas de 1970 e 1980 e sua chegada à Arquidiocese de Mariana tinha um grande significado para a população local, principalmente para os mais progressistas, que já vinham se articulando na mobilização social para a promoção das idéias da Teologia da Libertação e estavam ávidos de uma direção arquidiocesana progressista, que lhes desse melhores condições de atuação.

Para o padre Daniel, a mudança de uma postura mais conservadora para uma mais progressista já vinha acontecendo, mas ela se deu, sobretudo, com a chegada de Dom Luciano à Arquidiocese, o que é relatado por grande parte dos entrevistados. Para o padre Douglas, a chegada de Dom Luciano significou uma abertura para a atuação progressista:

15 Dom Luciano Pedro Mendes de Almeida foi bispo auxiliar da Arquidiocese de São Paulo, Região Belém, entre 1976 e 1988. Foi Secretário-Geral da CNBB entre 1979 e 1987, ano em que foi eleito Presidente da CNBB por dois mandatos consecutivos. 
O que a gente percebe é que há uma mudança na Arquidiocese de Mariana, sobretudo a partir da chegada de Dom Luciano, às vezes algumas questões que estavam mais abafadas, mais surdas, elas vão eclodir, e a forma como ele organizou a Diocese, essa tradição de assembléias pastorais, de encontro de presbíteros, não só os retiros, mas os encontros anuais, os presbíteros, discutir a Bíblia, os ministérios, questões pastorais, abriu mais o debate. A própria linha do jornal Pastoral, que sucedeu ao jornal Arquidiocesano mostra claramente uma perspectiva diferente, um foco diferente. Na realidade, o fato é outro, é uma Diocese mais aberta, digamos, assim, aquilo que é a caminhada da Igreja no Brasil, sobretudo da CNBB (padre Douglas) ${ }^{16}$.

O mesmo padre afirma que Dom Luciano significava um marco, um símbolo de mudança importante para a Arquidiocese de Mariana: "Então você vê, Dom Luciano estava atuante na Igreja no Brasil. Ele não estava em Mariana, mas a vinda dele pra Mariana era uma bandeira. A pessoa dele é uma bandeira, quando ele vem já significa isso. Quer dizer, todo mundo que tinha um pouco de informação percebia que a Arquidiocese estava dando uma guinada" (padre Douglas).

No entanto, a chegada de Dom Luciano não pode ser vista como a grande responsável pela consolidação das idéias progressistas, porque um grande grupo de pessoas já compartilhava de uma consciência insurgente, ou seja, acreditava que uma nova forma de religião era possível e viável. Contudo, os depoimentos dos padres vão de encontro às afirmações de Novaes (2002), que ressalta a importância da atuação dos bispos para a inserção e divulgação de novas idéias religiosas. Segundo Novaes (2002), a importância dos bispos se deu tanto durante a ditadura militar - em que era importante o bispo legitimar a atuação dos padres para que estes pudessem difundir as idéias da Teologia da Libertação - como na década de 1990, em que havia um "movimento restaurador", cujo objetivo era diminuir o poder de influência da Teologia da Libertação.

16 A entrevista com o padre Douglas foi realizada em outubro de 2004, na cidade de Mariana (MG). 


\section{A assessoria aos atingidos por barragens e religiosidade}

Assim, Dom Luciano era um nome importante para o movimento religioso progressista, que tem como destaque na região o apoio ao Movimento dos Atingidos por Barragens. Segundo o padre Claret, "o Dom Luciano e um grupo de padres dão todo apoio à defesa da vida do atingido, das populações ribeirinhas [...]". Em 1996, Dom Luciano reforçou sua preocupação com a situação dos atingidos por barragens na região ao convidar o agente da CPT-MG, Ricardo Ribeiro, para uma palestra visando discutir a questão das barragens, em que estavam presentes padres de municípios afetados pelas barragens da região Mariana Pastoral Leste (ROTHMAN, 2002, p. 7).

A preocupação dos padres, de Dom Luciano e dos agentes da CPT ligados à Igreja Católica revela a influência do pensamento religioso na percepção de justiça, solidariedade, cidadania e direito; assim, as idéias religiosas católicas configuraram-se como uma das principais fontes de sentido para a prática política e foram importantes como fator de agregação social ${ }^{17}$. Dessa forma, o pensamento religioso católico progressista foi legitimador da atuação de grupos católicos em apoio aos atingidos. Nesse sentido, houve interação entre valores religiosos e políticos.

Esses valores estão presentes nas palavras de Dom Luciano, em sua opinião sobre o Movimento dos Atingidos por Barragens, em que deixou evidente a legitimidade do trabalho do MAB-ARD ao afirmar que:

o Movimento do MAB aqui na nossa área é um movimento heróico, generoso, combativo e que dialoga, embora com dificuldades, e tem procurado defender os direitos da população, às vezes nem sempre os mesmos para todos. Às vezes, a pessoa é um posseiro e quer um ressarcimento, ou teve menos tempo no lugar, o equilíbrio dessas ações requer um organismo de referência, mas as intenções são justas e eu creio que devem ser respeitadas ${ }^{18}$.

17 Processo semelhante foi verificado por Leite (2003) no estudo do Movimento Popular de Favelas no Rio de Janeiro.

18 A entrevista com Dom Luciano foi realizada em novembro de 2004, em Mariana (MG). 
O MAB-ARD teve suas "raízes" em meados da década de 1990 , no contexto do surgimento de diversos projetos de empresas privadas interessadas na construção de usinas hidrelétricas. Nessa fase inicial, a presença de Ricardo Ferreira Ribeiro, "agente" da Comissão Pastoral da Terra (CPT) de Minas Gerais, foi de grande importância, uma vez que ele acompanhou os projetos de barragens na Zona da Mata entre 1995 e 1996, quando se afastou para cursar o doutorado.

Concomitante à presença de Ribeiro, o professor Franklin Daniel Rothman, junto com quatro outros professores da Universidade Federal de Viçosa que tinham experiência no campo político como militantes do Partido dos Trabalhadores, elaborou um projeto de extensão no intuito de apoiar as comunidades locais atingidas pelas barragens (ZHOURI \& ROTHMAN, 2008, p. 136). Alguns alunos da pós-graduação e da graduação da UFV se integraram ao grupo, que acabou somando a presença de um diácono ligado à Dimensão Social da Região Pastoral Mariana Leste, da Arquidiocese de Mariana - Antônio Claret.

Em 1997, a CPT continuou se fazendo presente com o trabalho de dois agentes da CPT - regional de Barbacena (ROTHMAN, 2002, p. 7). A preocupação de alguns padres com os atingidos era também evidente, tanto que em julho de 1997, com a intermediação do então diácono Claret, foi realizada uma reunião de padres e do assessor de Dom Luciano com Rothman, o coordenador do projeto de extensão da UFV, no qual aqueles buscavam orientações sobre a interação de padres com as atividades de assessoria, com o intuito de atender melhor às comunidades atingidas do Alto Rio Doce (idem, p. 9).

Esses grupos, junto com alguns líderes das comunidades atingidas e com um ambientalista, presidente da ONG Associação de Pescadores e Amigos do Rio Piranga (Asparpi), transformaram-se em uma rede de pessoas que compartilhavam de uma identidade coletiva - a de serem sensíveis aos problemas vividos pelas comunidades atingidas pelas barragens - e de uma consciência insurgente, uma vez que acreditavam que uma mobilização social era viável e se fazia necessária aos atingidos.

Dom Luciano também afirmou ter-se empenhado em todas as instâncias possíveis para ajudar às pessoas atingidas pelas barragens. 
Essas atitudes de Dom Luciano e de alguns padres da Arquidiocese foram importantes, pois, com elas, foram obtidas salas, telefone e secretária, recursos muito relevantes para a consolidação do MAB do Alto Rio Doce de Minas Gerais (MAB-ARD) ${ }^{19}$.

Em 1997, Dom Luciano e o padre João do Carmo Macedo mostraram, no jornal oficial da Arquidiocese, como esta se posicionava diante da iminente construção de barragens:

Posição da Arquidiocese de Mariana

No desejo de estar a serviço da Vida, a Arquidiocese de Mariana fica ao lado dos atingidos e contra a construção de barragens:

- juntando-se a entidades, grupos e pessoas que já estão trabalhando na conscientização e organização dos Atingidos;

- visitando e solidarizando-se com os atingidos, ajudando-os a enfrentar os problemas e defender os seus direitos;

- denunciando publicamente, sempre que houver manipulação, agressão ou exclusão de pessoas atingidas (O Pastoral, ano VI, n. 67, p. 3, jan.1997).

Portanto, na medida em que agentes pastorais e padres, já imbuídos de uma visão de mundo mais justa pelas idéias da Teologia da Libertação e do Mobon, tomaram conhecimento dos impactos sociais negativos associados ao processo de construção de barragens na região, foram adotando um frame de injustiça social e um compromisso de agir na defesa dos atingidos por barragens.

Diante de tantos grupos preocupados e atuantes no intuito de proporcionar maior poder de barganha aos atingidos, consolidou-se, em 1999, a idéia de que a presença de uma organização regional, que depois se tornou um importante instrumento de organização e articulação do Movimento, seria de grande importância para a defesa dos direitos dos atingidos, devido à proliferação de projetos de consórcios privados para a construção de hidrelétricas na região. Nesse sentido, foi criado o Conselho Regional dos Atingidos por

19 O estudo de Rothman (1996) demonstrou a importância de recursos da Igreja para a emergência do Movimento Regional dos Atingidos por Barragens do Sul do Brasil. 
Barragens do Alto Rio Doce, cuja secretaria funcionava em um prédio anexo à Igreja Matriz de Ponte Nova e sua secretária era paga pela Arquidiocese de Mariana (ZHOURI \& ROTHMAN, 2008, p. 140).

A presença e influência do $M A B$ nacional na região assumiram importância maior a partir de 2001, com a presença de suas lideranças, que, inclusive, promoveram cursos de formação de lideranças. Assim, tornou-se importante a presença de assessores do MAB Nacional e de setores progressistas da Arquidiocese de Mariana e da UFV para que se criasse uma estrutura de mobilização para a consolidação do MAB-ARD. Vale destacar que, embora o trabalho do bispo Dom Luciano tivesse sido de extrema importância na defesa das populações atingidas pelas barragens, as articulações progressistas anteriores foram importantes para a constituição da idéia de que a religião tem uma importante função social a cumprir, o que foi fundamental para a legitimação do trabalho do arcebispado.

Não obstante o fato de grupos da Arquidiocese de Mariana empenharem-se na consolidação do MAB-ARD, a ação dos padres e religiosos engajados com os atingidos é, segundo padre Claret, um trabalho secular. Ele faz uma distinção entre seu trabalho com os atingidos e o trabalho como padre. No MAB, ele se vê "como alguém que está junto que se preocupa e motiva o pessoal. Mas não como padre, não, e isso é uma coisa bem tranquiila".

No que se refere à dinâmica do MAB-ARD e à sua articulação com a Arquidiocese de Mariana, surgem diferenciações na forma de se obter maiores benefícios em prol da população atingida pelas barragens. O padre Claret explica essa diferenciação ao afirmar que:

o método do MAB é da organização, da informação e do enfrentamento, né? E o método que é tradicionalmente usado pela Igreja, e acho que é o método que geralmente toda autoridade defende, é justamente o da informação sim, organização sim, mas do enfrentamento nem tanto. E aí existe esta diferença. E o Dom Luciano é uma pessoa muito sensível, defendendo também esta conversa com o outro lado. Em termos estratégicos, assim, não é que você não vai conversar com o adversário. Não é neste sentido. Mas, em termos estratégicos, você tem que manter uma distância e isso nem sempre ele entende, mas é uma coisa assim muito tranqüila. 
Dessa forma, os métodos adotados pelo MAB-ARD e aquele proposto pelo arcebispado são diferenciados, e as empresas empreendedoras interessadas e engajadas na construção das hidrelétricas, percebendo essas diferenciações, tentam colocar o Movimento contra autoridades arquidiocesanas, objetivando diminuir a legitimidade de padres e lideranças católicas diretamente envolvidas na organização e mobilização dos atingidos pelas barragens.

De acordo com o padre Claret, empresas tentam criar dificuldades de relacionamento do MAB-ARD com o arcebispado porque sabem da relevância do apoio da Arquidiocese ao Movimento. Segundo o padre, houve um momento em que "[...] o jornal daqui da cidade veio e publicou como se estive havendo uma briga entre Dom Luciano e nós. Na verdade não é nada disso, é só uma diferença de método".

Essas diferenças de método de trabalho refletem a posição institucional da Igreja Católica, que procura ser um espaço de diálogo e entendimento mútuo, e do MAB, que, em determinados momentos, adota um posicionamento de maior enfrentamento aos grupos empreendedores. Embora a Arquidiocese invista na tentativa de evitar um conflito entre as partes e de passar a imagem dela como um espaço do diálogo, Dom Luciano deixava evidente a preocupação com os atingidos pelas barragens, como visto nos relatos anteriores.

Essa preocupação é especialmente maior com a população mais pobre, porque, segundo Dom Luciano, a construção das barragens traz grandes consequiências às:

[...] famílias geralmente pobres, porque uma ou outra aquinhoada, era inicialmente bem remunerada ou compensada, já para as famílias isoladas e pequenas, havia necessidade de uma associatividade maior de as pessoas conhecerem seus direitos, defenderem seus direitos, naturalmente também cumprirem as exigências que a elas cabem. Então foi surgindo esse agrupamento de pessoas atingidas por barragem, depois consolidou-se o movimento MAB, Movimento dos Atingidos por Barragem (Dom Luciano).

O MAB-ARD iniciou o trabalho de apoio às comunidades primeiramente informando-se sobre o objetivo da construção de 
barragens na região, por meio dos mapas fornecidos pela $\mathrm{FEAM}^{20}$, num documento público que qualquer pessoa interessada pode obter - assim, ficaram sabendo dos projetos de barragens. Segundo o padre Claret, o contato foi feito com a população que seria afetada pela construção da hidrelétrica ou as pessoas que seriam atingidas procuravam o MAB no intuito de se organizar e obter mais informações sobre a construção dessas barragens.

Depois desse primeiro contato, o MAB-ARD passou a trabalhar com a população com o intuito de prepará-la para defender seus direitos. Com esse objetivo, foram organizados conselhos, que atualmente reúnem-se de dois em dois meses para discutir os projetos e acompanhar a nova situação que se coloca.

Nessa etapa em que os grupos se encontram para discutir suas dificuldades e a situação dos projetos em andamento, as reuniões se tornam um importante momento de socialização e discussão das necessidades urgentes e da situação vivida pelos atingidos. Esse espaço de reunião é importante na construção da identidade coletiva de atingido, pois essa identidade se constrói com seus membros vendo-se em grupo. Nesse sentido, nas reuniões são compartilhados os problemas e a identidade comum que os unem, ficando mais evidente o fato de serem atingidos pelas barragens.

Segundo o padre Claret, eles se reúnem, no início, mais para ouvir e "depois para organizar o grupo de base, que é o ponto central do Movimento". Nessa perspectiva, "as pessoas que moram mais próximo se organizam em cinco, dez famílias e ali as pessoas decidem o quando vão reunir, se de mês em mês, ou quando precisar, e discutem os assuntos das barragens".

Dessa forma, concorda-se, aqui, com o argumento de Comerford (1999, p. 47), para quem as reuniões, além de sua dimensão instrumental de tomar decisões ou discutir interesses dos grupos, "criam espaço de sociabilidade que contribui para a consolidação de redes de relações que atravessam a estrutura formal das organizações...”.

20 Fundação Estadual do Meio Ambiente de Minas Gerais. Órgão responsável pela análise dos estudos de impacto ambiental das barragens e pela licença ou embargo da construção da barragem. 
Assim, as reuniões para discussão a respeito das posturas e decisões a serem tomadas a respeito dos atingidos são pensadas:

[...] como um momento fundamental de participação, de democracia e de organização, uma oportunidade para que todos falem abertamente o que pensam, um espaço para tornar públicos os problemas e dilemas da organização de seus membros, e ainda um espaço para aprendizado e para conscientização através da discussão participativa, reflexiva e livre (COMERFORD, 1999, p. 49).

Dentro dessa perspectiva, é importante lembrar que as reuniões desses grupos são de suma importância para a construção da consciência insurgente, tendo em vista que, apesar de as decisões de participar das reuniões do grupo serem individuais, é no grupo das relações sociais e nas redes de ligação em que a pessoa se insere que a decisão é ativada e sustentada (TARROW, 1998).

O padre Claret declara que nas reuniões vão ocorrendo os processos de informação e de conscientização e que, a partir daí, o pessoal "vai ficando mais à vontade e vai abrindo a mente e vai abrindo a visão também e vai percebendo que a luta é maior e se engaja de verdade":

[...] Naqueles lugares em que existe a experiência principalmente das CEBs, esse passo parece que [...] acontece de uma forma mais tranquiila. Esse passo da visão do interesse mais individual, quer dizer a minha casa, a minha terra, o rio do qual preciso para a questão do bem comum, da defesa das pessoas, do entendimento de como funciona o setor elétrico (padre Claret).

Vale lembrar da afirmação de Novaes (2002), de que as CEBs constituem-se como espaço propício para unir fé e vida, pois, na ótica dessas comunidades, a missão religiosa envolve participação efetiva tanto na transformação da Igreja - instituição - quanto na sociedade em um sentido mais genérico. Nesse sentido, muitos desses grupos reúnem-se para ler a Bíblia "à luz da realidade local”, e isso ajuda a entender como a prática religiosa das CEBs, antes da presença do MAB-ARD, foi fundamental para facilitar a construção do frame de injustiça, conforme destacou o padre Claret. 
Nessa mesma perspectiva, o padre Claret afirma que, no MABARD, a "questão religiosa vai junto".

Aí, Deus é "usado" entre aspas tanto para um lado quanto para o outro, né? Quando as pessoas vão se despertando, isso não tem como tirar, porque realmente, fica junto mesmo. $O$ pessoal todo é muito religioso, [...] num certo sentido toda essa mística, isso está muito presente, o fator religioso também. Então, assim, isso fica junto. E quanto as pessoas começam a se despertar, então começa, por exemplo, a buscar texto na Bíblia. Principalmente onde tem CEBs. E a experiência religiosa vai ajudando a pessoa a ir para frente. Isso vai sempre muito junto. Nas nossas manifestações, ocupações, quando o bicho está pegando mesmo e tal, o pessoal celebra, canta, é um processo muito interessante. $O$ fator religioso é muito presente (padre Claret).

O trabalho com os atingidos e sua visão de mundo acabam sendo permeados pelos valores religiosos; assim, configura-se uma situação em que a religião acaba sendo uma referência de extrema importância para a prática política. Como afirma Novaes (2002, p. 64), "as pessoas não se envolvem em política apenas com 'a razão'. Aqueles que 'fazem' e/ou 'participam' da política levam consigo suas dúvidas, crenças religiosas, símbolos mobilizadores partilhados”.

De acordo com esse mesmo enfoque, na construção de uma consciência insurgente com os atingidos pelas barragens:

[...] uma coisa que a gente percebe, a gente vai aprendendo; sem considerar os valores que as pessoas têm, a gente não consegue ir para frente não. $O$ fator religioso é essencial. Então, assim, fazer de tudo não é para manipular. Mas essa é uma experiência interessante que justamente as CEBs tentam fazer. Uma interpretação mais crítica da Bíblia, mais contextualizada, né? Sem considerar o fator religioso, principalmente numa região marcada pela questão religiosa, as pessoas não conseguem muito ir para a frente (padre Claret).

Essa citação deixa em evidência que a religião e os simbolismos religiosos que articulam fé e vida foram fundamentais na constituição de uma consciência insurgente, que tem sido fundamental no sentido de dar legitimidade ao Movimento, já que o pertencimento religioso é de extrema relevância nas percepções de cidadania, justiça, direitos humanos e dignidade. 


\section{Resumo e conclusões}

Este trabalho analisou as ações de grupos progressistas da Arquidiocese de Mariana durante o arcebispado de Dom Oscar de Oliveira (1959-1988), bem como o processo de transformações pelas quais passou a instituição no sentido de se tornar mais progressista na década de 1990. O objetivo do estudo foi entender como, em um momento em que a cúpula da Igreja Católica procurava diminuir o ativismo político do catolicismo (na década de 1990), a Arquidiocese de Mariana mostrava-se mais receptiva às idéias da Teologia da Libertação.

Destacou-se a abordagem teórica da mobilização política como uma vertente explicativa para tratar das transformações progressistas, ideológicas e institucionais na Arquidiocese de Mariana e a influência dessas correntes na mobilização e organização dos atingidos por barragens no Alto Rio Doce e Zona da Mata mineira.

Como observado, a Arquidiocese de Mariana foi, e ainda é, uma instituição de grande relevância nacional, podendo ser caracterizada como uma instituição conservadora e aliada da elite brasileira até os anos de 1980, momento em que se criou uma oportunidade política que facilitou a emergência de idéias progressistas, na medida em que grupos de católicos que se identificavam com as posturas progressistas da Igreja Católica mobilizaram-se no sentido de promover idéias religiosas progressistas na Arquidiocese.

As dificuldades eram grandes, tendo em vista o clero conservador e a população como um todo, que estava acostumada a manifestações religiosas sem manifestações contra o status quo. No entanto, mesmo diante desses constrangimentos, ocorreu uma convergência dos processos de redemocratização do país na década de 1980, pela difusão de idéias da Teologia da Libertação por meio das Comunidades Eclesiais de Base e do Mobon na diocese vizinha e de um crescente número de padres em busca de idéias de justiça social. Os grupos progressistas se articularam em redes sociopolíticas com afinidades pessoais e ideológicas, que se constituíram numa estrutura de mobilização que possibilitou a formação de uma consciência insurgente, a qual fortaleceu a idéia da importante função social da religião e o compromisso de contribuir para uma religiosidade e práticas sociais diferentes. 
A chegada e a gestão de Dom Luciano proporcionaram a oportunidade política e o espaço institucional que permitiram que essas redes sociopolíticas e ideológicas preexistentes, muitas vezes articuladas às idéias e ações do Mobon, transformassem a Arquidiocese de Mariana numa instituição com idéias e práticas mais progressistas.

Portanto, coerentes com a abordagem da mobilização política, os dados indicaram que uma estrutura de oportunidade política favorável propiciou as condições que permitiram o surgimento e a difusão de idéias e práticas religiosas e políticas numa instituição tradicionalmente conservadora; afinidades pessoais e ideológicas e interação de ativistas leigos e religiosos contribuíram para a formação de redes e estruturas de mobilização, que difundiram idéias, práticas e atividades progressistas; processos de framing contribuíram para que os ativistas assimilassem essas idéias progressistas e as aplicassem a uma visão de mundo de uma sociedade nova e mais justa. Por sua vez, a consciência insurgente dos leigos e padres progressistas, no contexto das mudanças na Arquidiocese, contribuiu para a emergência e a consolidação do Movimento dos Atingidos por Barragens do Alto Rio Doce de Minas Gerais.

Recebido em 15.3.2007

Aprovado em 30.7.2007

\section{Referências bibliográficas}

BOFF, L. \& BOFF, C. Como fazer Teologia da Libertação. Petrópolis: Vozes, 2001.

COMERFORD, J. C. Fazendo a luta: sociabilidade, falas e rituais na construção de organizações camponesas. Rio de Janeiro: Relume Dumará, 1999.

GAIGER, L. I. Agentes religiosos e camponeses sem terra no Sul do Brasil. Petrópolis: Vozes, 1987.

GOHN, M. G. Teorias dos movimentos sociais: paradigmas clássicos e contemporâneos. São Paulo: Loyola, 2002.

HIGUET, E. O misticismo na experiência católica. In: Religiosidade popular e misticismo no Brasil. São Paulo: Paulinas, 1984. 
IOKOI, Z. M. G. Igreja e camponeses: Teologia da Libertação e movimentos sociais no campo, Brasil e Peru, 1964-1986. São Paulo: Hucitec, 1996.

LEITE, M. P. Novas relações entre identidade religiosa e participação política no Rio de Janeiro hoje: o caso do Movimento Popular de Favelas. In: BIRMAN, P. (org.). Religião e espaço público. São Paulo: Attar, 2003.

LESBAUPIN, I. Comunidade de base e mudança social. Estudos de Política e Teoria Social, v. 3, p. 54-79, 2000.

LESBAUPIN, I.; RIBEIRO, L.; FIORIN, N. \& RODRIGUES, S. Revisitando as CEBs: um estudo no Rio de Janeiro e em Minas Gerais. Religião e Sociedade, v. 24, n. 1, p. 142-176, 2004.

MARIZ, C. L. Católicos da libertação, católicos renovados e neopentecostais. Cadernos CERIS, n. 2, out.2001.

MCADAM, D. Political Process and the Development of Black Insurgency, 1930-1970. Chicago: University of Chicago, 1982.

MCADAM, D.; MCCARTHY, J. D. \& ZALD, M. N. Comparative Perspectives on Social Movements - Political Opportunities, Mobilizing Structures and Cultural Framings. Cambridge: Cambridge University, 1996a.

. Introduction: Opportunities, Mobilizing Structures, and Framing Processes - toward a Synthetic, Comparative Perspective on Social Movements. In: MCADAM, D.; MCCARTHY, J. D. \& ZALD, M. N. Comparative Perspectives on Social Movements - Political Opportunities, Mobilizing Structures and Cultural Framings. Cambridge: Cambridge University, 1996b.

MCADAM, D.; TARROW, S. \& TILLY, C. Dynamics of Contention. Cambridge: Cambridge University, 2001.

MCCARTHY, J. D. Constraints and Opportunities in Adopting, Adapting, and Inventing. In: MCADAM, D.; MCCARTHY, J. D. \& ZALD, M. N. Comparative Perspectives on Social Movements - Political Opportunities, Mobilizing Structures and Cultural Framings. Cambridge: Cambridge University, 1996.

MELUCCI, A. Challenging Codes: Collective Action in the Information Age. Cambridge: Cambridge University, 1996. 
MELUCCI, A. A invenção do presente: movimentos sociais nas sociedades complexas. Petrópolis: Vozes, 2001.

NOVAES, R. Crenças religiosas e conviç̧ões políticas: crenças e passagens. In: FRIDMAN, L. C. Política e cultura, século XXI. Rio de Janeiro: Relume-Dumará, 2002.

MOBON. Religião na política. Dom Cavati: Movimento Boa Nova, 198 ?

OLIVEIRA, P. R. Religião e dominação de classe: gênese e função do catolicismo romanizado no Brasil. Petrópolis: Vozes, 1985.

PETRINI, J. C. CEBs: um novo sujeito popular. Rio de Janeiro: Paz e Terra, 1984.

PIRES, M. C. De juiz a infrator: notas sobre o Juízo Eclesiástico do Bispado de Mariana (século XVIII). Revista de História, Ouro Preto, n. 7, p. 260-269, 1997.

PIVEN, F. F. \& CLOWARD, R. A. Poor People's Movements: Why They Succeed, How They Fail. New York: Vintage, 1979.

PRANDI, R. \& SOUZA, A. R. A carismática despolitização da Igreja Católica. In: PIERUCCI, A. F. \& PRANDI, R. A realidade das religiões no Brasil: religião, sociedade e política. São Paulo: Hucitec, 1996.

ROTHMAN, F. D. A emergência do Movimento dos Atingidos pelas Barragens da Bacia do Rio Uruguai, 1979-1983. In: NAVARRO, Z. (org.). Política, protesto e cidadania no campo: as lutas sociais dos colonos e trabalhadores rurais no Rio Grande do Sul. Porto Alegre: UFRGS, 1996.

. Mediações nas lutas de resistência aos projetos de barragem no Sudeste de Minas Gerais. Trabalho apresentado no VI Congresso Latino-Americano de Sociologia Rural, realizado em Porto Alegre (Rio Grande do Sul), de 25 a 29 de novembro de 2002.

. Political Process and Peasant Opposition to Large Hydroelectric Dams: the Case of the Rio Uruguai Movement in Southern Brazil, 1979 to 1992. Madison. Tese (Doutorado em Sociologia). University of Wisconsin.

SCHERER-WARREN, I. Redes de movimentos sociais. São Paulo: Loyola, 1996. 
SMITH, C. The Emergence of Liberation Theology: Radical Religion and Social Movement Theory. Chicago: University of Chicago, 1991.

TARROW, S. States and Opportunities: the Political Structuring of Social Movements. In: MCADAM, D.; MCCARTHY, J. D. \& ZALD, M. N. Comparative Perspectives on Social Movements - Political Opportunities, Mobilizing Structures and Cultural Framings. Cambridge: Cambridge University, 1996.

TARROW, S. Power in Movement: Social Movements and Contentious Politics. Cambridge: Cambridge University, 1998.

VALENTE, A. L. E. F. O negro e a Igreja Católica: o espaço concedido, um espaço reivindicado. São Paulo. Tese (Doutorado em Antropologia Social). Universidade de São Paulo, 1989.

ZHOURI, A. \& ROTHMAN, F. D. Assessoria aos Atingidos por Barragens em Minas Gerais. Desafios, limites e potenciais. In: ROTHMAN, F. D. (org.). Vidas alagadas: conflitos socioambientais, licenciamento e barragens. Viçosa: UFV, 2008.

\section{Fonte documental}

O Pastoral, Mariana, 1995-1997. 
